\title{
Antibiotics-First Strategy versus Appendectomy in the Management of Acute Appendicitis
}

\author{
Yubin Kou, Xiaoping Chen* \\ Shanghai Baoshan District Hospital of Integrated Traditional and Western Medicine, Shanghai, China \\ Email: *koagrace@sina.com
}

How to cite this paper: Kou, Y.B. and Chen, X.P. (2017) Antibiotics-First Strategy versus Appendectomy in the Management of Acute Appendicitis. Open Access Library Journal, 4: e3335.

http://dx.doi.org/10.4236/oalib.1103335

Received: December 27, 2016

Accepted: January 20, 2017

Published: January 23, 2017

Copyright (C) 2017 by authors and Open Access Library Inc.

This work is licensed under the Creative Commons Attribution International License (CC BY 4.0).

http://creativecommons.org/licenses/by/4.0/

\begin{abstract}
Acute appendicitis is the most common cause of acute abdominal disorders requiring surgery. The mainstay of treatment is an appendectomy for more than 100 years. However, symptoms of acute appendicitis confuse many other conditions making diagnosis a challenge. In addition, as with all operations, postoperative complications exist, including wound infections, intra-abdominal abscesses, ileus and adhesions. For some specific patients (the first trimester of pregnancy or who have contraindications), surgery is not the best choice. So it is important to confirm if antibiotics-first approach is effective and may be used as an alternative treatment for appendectomy.
\end{abstract}

\section{Subject Areas \\ Emergency \& Critical Care}

\section{Keywords}

Acute Appendicitis, Appendectomy, Antibiotics

\section{Introduction}

Acute appendicitis is one of the most common acute abdominal conditions that need urgent surgical treatment, and meantime acute appendicitis remains the most common cause of the acute abdomen in young adults. Traditionarily the mainstay of treatment is an appendectomy. However, appendicitis can be notoriously difficult to diagnose, and there exists a negative appendectomy rate of $10 \%-20 \%$ despite the use of preoperative computed tomography (CT) with high sensitivities and specificities. Our article talks about that if Antibiotics-First approach can cure acute appendicitis and avoid appendectomy, it doesn't increase complications. 


\section{Pathophysiology}

As well known, the appendix is an independent organ and has abundant lymphoid tissue. It participates in the body's immune function, cellular and humoral immunity and secretes several digestive enzymes. Its function reaches its peak at the age of 20 to 30 and after falling down rapidly and completely disappears after 60 years old. Some people therefore think that the adults were removed appendix with no effect on body's immune function. There is argument of whether the appendix has an active physiological function or is simply a vestigial organ for a long time. The observation that the appendix appears to have evolved independently of the cecum across many species supports a possible functional role [1] Bacteria sequestered in the appendix may act as a "safe house", repopulating the gut with healthy bacteria after massive diarrheal disease. For example, recurrence of Clostridium difficile infection (although not primary infection) is significantly more common among patients with a history of appendectomy than among those with an intact appendix [2] [3]. Recently, Wei PL and colleagues concluded that an increased risk of new-onset type II diabetes within 3 years after appendectomy was found in patients aged less than 65 years. The risk was highest in men and in those with complicated appendicitis [4].

Acute appendicitis is one of the most common acute abdominal conditions that need urgent surgical treatment, and meantime acute appendicitis remains the most common cause of the acute abdomen in young adults [5]. According to epidemiological survey data that approximately 300,000 people undergo appendectomy each year in the United States, with an estimated lifetime incidence of appendicitis that ranges from $7 \%$ to $14 \%$ [6] [7]. However, some appendicitis can be notoriously difficult to diagnose, and there exists a negative appendectomy rate of $10 \%-20 \%$ despite the use of preoperative computed tomography (CT) with high sensitivities and specificities [8] [9] [10] [11] [12]. In addition, as with all operations, postoperative complications exist, including wound infections, intra-abdominal abscesses, ileus and, in the longer term, adhesions. It is worth considering that the mainstay of treatment for other intra-abdominal inflammatory processes, such as diverticulitis, consists initially of conservative management with antibiotics [13]. We presume that antibiotic-first strategy maybe is one of the alternative treatment of appendectomy.

Appendicitis has historically been thought to result from luminal obstruction with a fecalith, distention, bacterial overgrowth, increased intraluminal pressure, and progressive tissue compromise with gangrene and perforation [14]. However, a more recent study measuring the luminal pressure in patients with appendicitis has shown increased pressure in only a quarter of the patients [15]. Similarly, in one study, fecaliths were identified in only $18 \%$ of the patients with appendicitis [16]. Growing evidence also suggests that perforation is not necessarily the inevitable result of appendiceal obstruction. Perforated appendicitis and nonperforated appendicitis appear to be different entities [17].

\section{Discussion}

Urgent appendectomy has been the mainstay of treatment for appendicitis since 
the late 1800s [18] [19], with a major advance made in the 1990s, when the use of the laparoscopic approach was suggested instead of the more conventional approach with special minimally invasive effect. In the United States, appendectomy is performed laparoscopically in $60 \%$ to $80 \%$ of cases, with hospitalization lasting an average of 1 to 2 days and a rate of complications of $1 \%$ to $3 \%$ [20] [21]. Sometimes appendicitis are difficult to be diagnosed, even with highquality ultrasonography and computed tomographic (CT) scan, and there exists misdiagnosed appendicitis rate of $10 \%-20 \%$. In addition, as with all operations, postoperative complications exist in the shorter and longer term.

With the use of broad-spectrum and sensitive antibiotics, whether antibiotics-first approach could be used as an alternative treatment for some special patients, for example, during the first trimester of pregnancy or who have contraindications to surgery, it is worthy of deeply clinical research.

The treatment of appendicitis with an antibiotics-first strategy [18] (1 g of cefuroxime twice daily and $500 \mathrm{mg}$ of metronidazole 3 times daily) was reserved for patients who were many days into an inflammatory process, with phlegmon and perhaps an abscess. Currently, a course of intravenous antibiotics is administered in these patients, and drainage of the abscess is performed in an attempt to avoid a more extensive operation, and operation will be potentially involving an ileocecectomy or ileostomy because of injury of ileum and cecum [22]. There are many pediatric centres which practise this approach in patients with advanced appendicitis. The authors reported that some cases were successful with conservative management, and some complicated cases were undertaken appendectomy [23] [24] [25]. Mason and colleagues [13] performed what he described as a systematic review of the published literature to assess whether it was necessary to perform surgery for appendicitis. Despite without detailed search methods or the databases used, he concluded that appendectomy may not be necessary for up to $70 \%$ of patients who could be appropriately treated with antibiotics. Mason's study does serve to question the traditional approach to as one alternative management of acute appendicitis.

Hansson and colleagues [26] performed an RCT to assess the use of antibiotic therapy versus appendectomy as the primary treatment of acute appendicitis. The antibiotic group is intravenous antibiotics (cefuroxime and metronidazole), the controlled group undertook operation (either open or laparocopic), and the primary outcomes were to be investigated. 91 of 161 patients in the antibiotic group were successful, other 70 cases receiving surgery. This compared with 13 of 167 patients in the surgical group who received antibiotic treatment and 154 cases received surgery. This was highlighted by the fact that patients who underwent surgery had a higher white cell count, pyrexia and peritonism compared with patients who were treated with antibiotics. Hansson and other authors in this article determined a treatment efficacy of $90.8 \%$ for antibiotic therapy and $89.2 \%$ for surgical treatment. The authors also demonstrated that the overall incidence of major complications was 3 times higher in patients who underwent surgery compared with those treated with antibiotics. However, once the diag- 
nosis of appendicitis becomes clear, then the patient should undergo an appendectomy. There was a study conducted an RCT to assess the role of antibiotics as the sole treatment for appendicitis. They reported an overall complication rate of $8.6 \%$ for surgical patients and $10 \%$ for patients treated with antibiotics; however, all complications in the antibiotic group developed after a subsequent appendectomy. Abes and colleagues [27] performed a retrospective analysis of patient records to assess the impact of non-operative treatment of acute appendicitis in children and concluded that antibiotics have a role in the management of localized abdominal tenderness. The authors found a statistically significant decrease in appendix size (radiologic imaging) in the antibiotic treatment group. They found that $93.7 \%$ ( 15 of the 16 patients) who received antibiotic treatment were managed successfully, with the only complication being recurrence in 2 patients who subsequently underwent appendectomies. Success with an antibiotics-alone approach in special patients (e.g., Navy personnel or seaman) in whom appendicitis developed while they were at sea (and did not have access to an operating room) supports this strategy in patients with uncomplicated appendicitis as well [28]. Common Features of Randomized Clinical Trials of "Antibiotics First" Regimens [18]. 1) Eligible patients are consenting adults who are not pregnant, do not have compromised immune function, and do not have certain implantable devices. 2) Patients have no evidence of abscess or perforation on imaging. 3) Patients have no evidence of sepsis or disseminated peritonitis on clinical examination. 4) Patients are admitted to a hospital, and intravenous antibiotics are administered for 48 hours. 5) Patients are assessed at intervals of 6 - 12 hours for progression of symptoms or development of sepsis. 6) Patients begin oral intake of food; when pain is well controlled, patients are discharged home with 7 days of oral antibiotics. 7) A patient proceeds to surgery if sepsis or shock, worsening fever, or disseminated peritonitis develops or if by 48 hours the patient's pain or elevated white-cell count is not reduced or the patient is unable to eat.

\section{Conclusions}

The documents listed above recommend trying an antibiotics-first approach treatment for acute appendicitis, but for the complications of cases with surgical intervention in time. Whether high risk of complications related to antibiotics-first approach compared with delayed surgery, and whether conservative management may have a role as a bridge to surgery. Stahlfeld and colleagues [29] performed a retrospective analysis of patients who had undergone appendectomy to determine there was no statistically significant difference between patients who underwent appendectomy within 10 hours of diagnosis and those who underwent appendectomy more than 10 hours after diagnosis. Another study [30], all of the participants being children, concluded that delaying surgery for up to 24 hours did not significantly affect complication rates. There was another observational study [31] similarly showed that a longer wait time to surgery was not associated with a higher risk of perforation but was associated with a higher risk of surgical site infection. Eventual appendectomy after initial, successful 
treatment with antibiotics occurred in $10 \%$ to $37 \%$ of the patients randomly assigned to the antibiotics-first strategy (mean time to appendectomy, 4.2 to 7 months in the three studies in which this outcome was reported [32] [33] [34]). Data from longer follow-up periods were unavailable, and therefore it is unclear whether the likelihood of appendectomy continued to increase or stabilize over time.

Although there appeared to be a growing trend toward the sole use of antibiotics and avoidance of surgery [35], several guidelines [36] [37] [38] recommend that "antibiotics-first strategy may be effective, but there is a higher chance of reoccurrence, not a widely accepted treatment, and may be used as an alternative treatment for specific patients for whom surgery is contraindicated".

\section{References}

[1] Smith, H.F., Parker, W., Kotzé, S.H. and Laurin, M. (2013) Multiple Independent Appearances of the Cecal Appendix in Mammalian Evolution and an Investigation of Related Ecological and Anatomical Factors. Comptes Rendus Palevol, 12, 339354. https://doi.org/10.1016/j.crpv.2012.12.001

[2] Im, G.Y., Modayil, R.J., Lin, C.T., et al. (2011) The Appendix May Protect against Clostridium Difficile Recurrence. Clinical Gastroenterology and Hepatology, 9, 1072 1077. https://doi.org/10.1016/j.cgh.2011.06.006

[3] American College of Surgeons (2014) Operation Brochures: Appendectomy.

[4] Wei, P.L., Tsai, M.C., Hung, S.H., et al. (2015) Risk of New-Onset Type II Diabetes after Appendectomy. British Journal of Surgery, 102, 1267-1271.

https://doi.org/10.1002/bjs.9875

[5] Fitzmaurice, G.J., McWilliams, B., Hurreiz, H. and Epanomeritakis, E. (2011) Antibiotics versus Appendectomy in the Management of Acute Appendicitis: A Review of the Current Evidence. Canadian Journal of Surgery, 54, 307-314. https://doi.org/10.1503/cjs.006610

[6] Weiss, A.J., Elixhauser, A. and Andrews, R.M. (2006) Characteristics of Operating Room Procedures in U.S. Hospitals, 2011: Statistical Brief \#170. Agency for Healthcare Research and Quality, Rockville.

[7] Addiss, D.G., Shaffer, N., Fowler, B.S. and Tauxe, R.V. (1990) The Epidemiology of Appendicitis and Appendectomy in the United States. American Journal of Epidemiology, 132, 910-925.

[8] Rao, P.M., Rhea, J.T., Rattner, D.W., et al. (1999) Introduction of Appendiceal CT: Impact on Negative Appendectomy and Appendiceal Perforation Rates. Annals of Surgery, 229, 344-349. https://doi.org/10.1097/00000658-199903000-00007

[9] Soreide, K. (2007) Should Antibiotic Treatment Replace Appendectomy for Acute Appendicitis? Nature Clinical Practice. Gastroenterology \& Hepatology, 4, 584-585. https://doi.org/10.1038/ncpgasthep0957

[10] Coursey, C.A., Nelson, R.C., Patel, M.B., et al. (2010) Making the Diagnosis of Acute Appendicitis: Do More Preoperative CT Scans Mean Fewer Negative Appendectomies? A 10-Year Study. Radiology, 254, 460-468.

https://doi.org/10.1148/radiol.09082298

[11] Chooi, W.K., Brown, J.A., Zelter P., et al. (2007) Imaging of Acute Appendicitis and Its Impact on Negative Appendectomy and Perforation Rates: the St. Paul's Experience. Canadian Association of Radiologists Journal, 58, 220-224. 
[12] Kim, K., Lee, C.C., Song, K.J., et al. (2008) The Impact of Helical Computed Tomography on the Negative Appendectomy Rate: A Multi-Center Comparison. Journal of Emergency Medicine, 34, 3-6. https://doi.org/10.1016/j.jemermed.2007.05.042

[13] Mason, R.J. (2008) Surgery for Appendicitis: Is It Necessary? Surgical Infections, 9, 481-488. https://doi.org/10.1089/sur.2007.079

[14] Wangensteen, O.H. and Dennis, C. (1939) Experimental Proof of the Obstructive Origin of Appendicitis in Man. Annals of Surgery, 110, 629-647. https://doi.org/10.1097/00000658-193910000-00011

[15] Arnbjörnsson, E. and Bengmark, S. (1983) Obstruction of the Appendix Lumen in Relation to Pathogenesis of Acute Appendicitis. Acta Chirurgica Scandinavica, 149, 789-791.

[16] Singh, J.P. and Mariadason, J.G. (2013) Role of the Faecolith in Modern-Day Appendicitis. Annals of the Royal College of Surgeons of England, 95, 48-51. https://doi.org/10.1308/003588413X13511609954851

[17] Andersson, R., Hugander, A., Thulin, A., Nystrom, P.O. and Olaison, G. (1994) Indications for Operation in Suspected Appendicitis and Incidence of Perforation. BMJ, 308, 107-110. https://doi.org/10.1136/bmj.308.6921.107

[18] Flum, D.R. (2015) Acute Appendicitis-Appendectomy or the "Antibiotics First" Strategy. New England Journal of Medicine, 372, 1937-1943. https://doi.org/10.1056/NEJMcp1215006

[19] O’Connell, P.R. (2008) The Vermiform Appendix. In: Williams, N.S., Bulstrode, C.J.K. and O'Connell, P.R., Eds., Bailey and Love's Short Practice of Surgery, 25th Edition, Hodder Arnold, London, 1204-1218.

[20] Andersson, R.E. (2014) Short-Term Complications and Long-Term Morbidity of Laparoscopic and Open Appendicectomy in a National Cohort. British Journal of Surgery, 101, 1135-1142. https://doi.org/10.1002/bjs.9552

[21] Papandria, D., Lardaro, T., Rhee, D., et al. (2013) Risk Factors for Conversion from Laparoscopic to Open Surgery: Analysis of 2138 Converted Operations in the American College of Surgeons National Surgical Quality Improvement Program. American Surgeon, 79, 914-921.

[22] Olsen, J., Skovdal, J., Qvist, N. and Bisgaard, T. (2014) Treatment of Appendiceal Mass-A Qualitative Systematic Review. Danish Medical Journal, 61, A4881.

[23] Owen, A., Moore, O., Marven, S. and Roberts, J. (2006) Interval Laparoscopic Appendices-Tomy in Children. Journal of Laparoendoscopic and Advanced Surgical Techniques, 16, 308-311. https://doi.org/10.1089/lap.2006.16.308

[24] Gillick, J., Mohanan, N., Das, L. and Puri, P. (2008) Laparoscopic Appendicectomy after Conservative Management of Appendix Mass. Pediatric Surgery International, 24, 299-301. https://doi.org/10.1007/s00383-007-2103-7

[25] Gillick, J., Velayudham, M. and Puri, P. (2001) Conservative Management of Appendix Mass in Children. British Journal of Surgery, 88, 1539-1542. https://doi.org/10.1046/j.0007-1323.2001.01912.x

[26] Hansson, J., Korner, U., Khorram-Manesh, A., Solberg, A. and Lundholm, K. (2009) Randomised Clinical Trial of Antibiotic Therapy versus Appendicectomy as Primary Treatment of Acute Appendicitis in Unselected Patients. British Journal of Surgery, 96, 473-481. https://doi.org/10.1002/bjs.6482

[27] Abes, M., Petik, B. and Kazil, S. (2007) Non-Operative Treatment of Acute Appendicitis in Children. Journal of Pediatric Surgery, 42, 1439-1442. https://doi.org/10.1016/j.jpedsurg.2007.03.049

[28] Wojciechowicz, K.H., Hoffkamp, H.J. and van Hulst, R.A. (2010) Conservative 
Treatment of Acute Appendicitis: An Overview. International Maritime Health, 62, 265-272.

[29] Stahlfeld, K., Hower, J., Homitsky, S., et al. (2007) Is Acute Appendicitis a Surgical Emergency? American Surgeon, 73, 626-629.

[30] Yardeni, D., Hirschi, R.B., Drongowski, R.A., et al. (2004) Delayed versus Immediate Surgery in Acute Appendicitis: Do We Need to Operate during the Night? Journal of Pediatric Surgery, 39, 464-469. https://doi.org/10.1016/j.jpedsurg.2003.11.020

[31] Teixeira, P.G., Sivrikoz, E., Inaba, K., Talving, P., Lam, L. and Demetriades, D. (2012) Appendectomy Timing: Waiting until the Next Morning Increases the Risk of Surgical Site Infections. Annals of Surgery, 256, 538-543. https://doi.org/10.1097/SLA.0b013e318265ea13

[32] Eriksson, S. and Granström, L. (1995) Randomized Controlled Trial of Appendectomy versus Antibiotic Therapy for Acute Appendicitis. British Journal of Surgery, 82, 166-169. https://doi.org/10.1002/bjs.1800820207

[33] Styrud, J., Eriksson, S., Nilsson, I., et al. (2006) Appendectomy versus Antibiotic Treatment in Acute Appendicitis: A Prospective Multicenter Randomized Controlled Trial. World Journal of Surgery, 30, 1033-1037. https://doi.org/10.1007/s00268-005-0304-6

[34] Vons, C., Barry, C., Maitre, S., et al. (2011) Amoxicillin plus Clavulanic Acid versus Appendicectomy for Treatment of Acute Uncomplicated Appendicitis: An Open-Label, Non-Inferiority, Randomised Controlled Trial. Lancet, 377, 1573-1579. https://doi.org/10.1016/S0140-6736(11)60410-8

[35] Friedell, M.L. and Perez-Izquierdo, M. (2000) Is There a Role for Interval Appendectomy in the Management of Acute Appendicitis? American Surgeon, 66, 1158-1162.

[36] American College of Surgeons (2014) Operation Brochures: Appendectomy.

[37] Society for Surgery of the Alimentary Tract. SSAT Patient Care Guidelines: Appendicitis. http://ssat.com/guidelines/Appendicitis.cgi

[38] Sartelli, M., Viale, P., Catena, F., et al. (2013) 2013 WSES Guidelines for Management of Intra-Abdominal Infections. World Journal of Emergency Surgery, 8, 3. https://doi.org/10.1186/1749-7922-8-3

Submit or recommend next manuscript to OALib Journal and we will provide best service for you:

- Publication frequency: Monthly

- 9 subject areas of science, technology and medicine

- Fair and rigorous peer-review system

- Fast publication process

- Article promotion in various social networking sites (LinkedIn, Facebook, Twitter, etc.)

- Maximum dissemination of your research work

Submit Your Paper Online: Click Here to Submit

Or Contact service@oalib.com 